International Journal of

Environmental Research and

Public Health

ISSN 1660-4601

www.mdpi.com/journal/ijerph

Article

\title{
Development of Primer Sets for Loop-Mediated Isothermal Amplification that Enables Rapid and Specific Detection of Streptococcus dysgalactiae, Streptococcus uberis and Streptococcus agalactiae
}

\section{Deguo Wang ${ }^{1, \dagger}$ and Yanhong Liu ${ }^{2, \dagger, *}$}

1 Henan Postdoctoral Research Base, Food and Bioengineering College, Xuchang University, Xuchang 461000, China; E-Mail: wangdg666@aliyun.com

2 Molecular Characterization of Foodborne Pathogens Research Unit, Eastern Regional Research Center, Agricultural Research Service, U.S. Department of Agriculture, 600 East Mermaid Lane, Wyndmoor, PA 19038, USA

$\dagger$ These authors contributed equally to this work.

* Author to whom correspondence should be addressed; E-Mail: yanhong.liu@ars.usda.gov; Tel.: +1-215-233-6587; Fax: +1-215-233-6581.

Academic Editor: Paul B. Tchounwou

Received: 28 March 2015 / Accepted: 8 May 2015 / Published: 26 May 2015

\begin{abstract}
Streptococcus dysgalactiae, Streptococcus uberis and Streptococcus agalactiae are the three main pathogens causing bovine mastitis, with great losses to the dairy industry. Rapid and specific loop-mediated isothermal amplification methods (LAMP) for identification and differentiation of these three pathogens are not available. With the 16S rRNA gene and 16S-23S rRNA intergenic spacers as targets, four sets of LAMP primers were designed for identification and differentiation of $S$. dysgalactiae, $S$. uberis and $S$. agalactiae. The detection limit of all four LAMP primer sets were $0.1 \mathrm{pg}$ DNA template per reaction, the LAMP method with $16 \mathrm{~S}$ rRNA gene and 16S-23S rRNA intergenic spacers as the targets can differentiate the three pathogens, which is potentially useful in epidemiological studies.
\end{abstract}


Keywords: loop-mediated isothermal amplification (LAMP); $16 \mathrm{~S}$ rRNA gene; 16S-23S rRNA intergenic spacer; Streptococcus dysgalactiae; Streptococcus uberis; Streptococcus agalactiae

\section{Introduction}

Bovine mastitis (BM) is a persistent and inflammatory reaction of the udder tissue, usually due to microbial infection [1]. The potentially fatal mammary gland infection is the most common disease in dairy cattle, which is also the most costly to the dairy industry [2]. According to the mode of transmission, mastitis can be classified as contagious mastitis (mainly caused by Staphylococcus aureus and Streptococcus agalactiae) or environmental mastitis (Streptococcus dysgalactiae, Streptococcus uberis, Streptococcus parauberis and Escherichia coli) [3]. Bovine mastitis can also be divided into clinical mastitis and sub-clinical mastitis, according to the clinical symptoms.

Clinical mastitis can be identified by abnormalities in the udder such as swelling, heat or redness as well as by milk abnormalities such as a watery appearance, flakes, or clots. In contrast, there is no visible sign of infection when cow is infected with subclinical mastitis, and a method of rapidly identifying sub-clinical mastitis is needed for the control of infection in the herd $[4,5]$.

Polymerase chain reaction (PCR) assays had been developed to identify pathogens in bovine mastitis [6], this molecular method used for analyzing pure microbial cultures is very effective [7], but limited by PCR inhibitors present in biological and food samples, which results in reduction of the detection sensitivity or production of false-negative results [8,9]. Therefore, rapid, sensitive, and cost-effective methods are needed for identification and differentiation of bovine mastitis pathogens.

Loop-mediated isothermal amplification (LAMP) developed by Notomi et al. in 2000 [10], can rapidly amplify nucleic acids by utilizing a DNA polymerase enzyme with high strand displacement activity and two pairs of primers recognizing six independent sequences of a target gene under isothermal conditions with great specificity and sensitivity. Moreover, in 2002 Nagamine et al. advanced this method by introducing forward loop primers that accelerated the LAMP reaction [11]. Due to the cost effectiveness and sensitivity of LAMP, there has been significant interest in application of this method toward basic research in medicine and environmental testing, as well as point-of-care testing and diagnosis of infectious diseases in clinical settings [12]. LAMP has also been widely applied in pathogen detection including Escherichia coli O157:H7 [13], Actinobacillus actinomycetemcomitans [14], Mycobacterium tuberculosis [15], S. pneumonia [16], and Listeria monocytogenes [17]. More recently, LAMP has been used successfully to detect the bovine mastitis pathogens Staphylococcus aureus [18, 19] and S. agalactiae [20].

In this paper, a LAMP method was developed for the identification and differentiation of S. dysgalactiae, S. uberis and S. agalactiae. Four sets of LAMP primers were designed targeting the 16S rRNA gene and 16S-23S rRNA intergenic spacers, and tested for the sensitivity and specificity in LAMP reactions. 


\section{Experimental Section}

\subsection{Bacterial Strains, Culture Conditions and Genomic DNA Isolation}

Twenty five bacterial strains including $S$. dysgalactiae subsp. equisimilis strain ATCC 9542, S. uberis ATCC 700407 and S. agalactiae ATCC 27956 used in this study are listed in Table 1. Listeria strains were cultured overnight at $37^{\circ} \mathrm{C}$ in Difco ${ }^{\mathrm{TM}}$ Buffered Listeria Enrichment Broth Base (Becton, Dickinson and Company, Franklin Lakes, NJ, USA) while other strains were cultured overnight at $37^{\circ} \mathrm{C}$ in Luria-Bertani (LB) broth. Genomic DNA from the overnight cultures was extracted using DNeasy ${ }^{\circledR}$ Blood \& Tissue Kit (Qiagen, Inc., Valencia, CA, USA) according to the manufacturer's instructions.

Table1. Bacterial strains used in this study and specificity of four LAMP primer sets.

\begin{tabular}{lcccc}
\hline \multirow{2}{*}{ Bacterial Strains } & $\begin{array}{c}\text { Primer } \\
\text { Set I }\end{array}$ & $\begin{array}{c}\text { Primer } \\
\text { Set II }\end{array}$ & $\begin{array}{c}\text { Primer Set } \\
\text { III }\end{array}$ & $\begin{array}{c}\text { Primer Set } \\
\text { IV }\end{array}$ \\
\hline Streptococcus dysgalactiae ATCC 9542 & $4{ }^{\mathbf{a} / 4} \mathbf{b}$ & $4 / 4$ & $0 / 4$ & $0 / 4$ \\
Streptococcus uberis ATCC 700407 & $4 / 4$ & $0 / 4$ & $4 / 4$ & $0 / 4$ \\
Streptococcus agalactiae ATCC 27956 & $4 / 4$ & $0 / 4$ & $0 / 4$ & $4 / 4$ \\
Staphylococcus aureus ATCC 25923 & $0 / 4$ & $0 / 4$ & $0 / 4$ & $0 / 4$ \\
Listeria monocytogenes J2-020 (1/2a) & $0 / 4$ & $0 / 4$ & $0 / 4$ & $0 / 4$ \\
Listeria monocytogenes J2-064 (1/2b) & $0 / 4$ & $0 / 4$ & $0 / 4$ & $0 / 4$ \\
Listeria monocytogenes J1-169 (3b) & $0 / 4$ & $0 / 4$ & $0 / 4$ & $0 / 4$ \\
Listeria monocytogenes J1-049 (3c) & $0 / 4$ & $0 / 4$ & $0 / 4$ & $0 / 4$ \\
Listeria monocytogenes M1-004 (N/A) & $0 / 4$ & $0 / 4$ & $0 / 4$ & $0 / 4$ \\
Listeria monocytogenes J1-094 (1/2c) & $0 / 4$ & $0 / 4$ & $0 / 4$ & $0 / 4$ \\
Listeria monocytogenes C1-115 (3a) & $0 / 4$ & $0 / 4$ & $0 / 4$ & $0 / 4$ \\
Listeria monocytogenes J1-031 (4a) & $0 / 4$ & $0 / 4$ & $0 / 4$ & $0 / 4$ \\
Listeria monocytogenes W1-110 (4c) & $0 / 4$ & $0 / 4$ & $0 / 4$ & $0 / 4$ \\
Listeria monocytogenes ATCC19115 (4b) & $0 / 4$ & $0 / 4$ & $0 / 4$ & $0 / 4$ \\
Listeria innocua ATCC51742 & $0 / 4$ & $0 / 4$ & $0 / 4$ & $0 / 4$ \\
Escherichia coli O157:H7 933 & $0 / 4$ & $0 / 4$ & $0 / 4$ & $0 / 4$ \\
Listeria invanovii ATCC49954 & $0 / 4$ & $0 / 4$ & $0 / 4$ & $0 / 4$ \\
Salmonella typhimuriam & $0 / 4$ & $0 / 4$ & $0 / 4$ & $0 / 4$ \\
Escherichia coli O111:H8 & $0 / 4$ & $0 / 4$ & $0 / 4$ & $0 / 4$ \\
Salmonella enterica serotype Newport & $0 / 4$ & $0 / 4$ & $0 / 4$ & $0 / 4$ \\
Escherichia coli O26:H11 & $0 / 4$ & $0 / 4$ & $0 / 4$ & $0 / 4$ \\
Escherichia coli O121:H19 & $0 / 4$ & $0 / 4$ & $0 / 4$ & $0 / 4$ \\
Escherichia coli O103:H2 & $0 / 4$ & $0 / 4$ & $0 / 4$ & $0 / 4$ \\
Escherichia coli O145:H2 & $0 / 4$ & $0 / 4$ & $0 / 4$ & $0 / 4$ \\
Escherichia coli O45:H12 & $0 / 4$ & $0 / 4$ & $0 / 4$ & $0 / 4$ \\
\hline
\end{tabular}

${ }^{\mathbf{a}}$ Numbers of LAMP positive; ${ }^{\mathbf{b}}$ Numbers of total experiments carried out.

\subsection{Primer Design}

Sequences targeting the specific 16S rRNA gene (GenBank Locus: AP011114.1) of Streptococcus spp., the 16S-23S rRNA intergenic spacer (GenBank Locus: AY351330.1) of S. dysgalactiae subsp. equisimilis strain ATCC 9542, the 16S-23S rRNA intergenic spacer (GenBank Locus: AY347567.1) 
of $S$. uberis ATCC 700407, and the 16S-23S rRNA intergenic spacer (GenBank Locus: DQ204552.1) of $S$. agalactiae ATCC 27956 were used to design primers. Four sets of LAMP primers designed using PrimerExplorer 4 and Oligo 7 are listed in Table 2 [21].

Table 2. Primers for identification and differentiation of $S$. dysgalactiae, $S$. uberis and $S$. agalactiae with LAMP method.

\begin{tabular}{|c|c|c|}
\hline Target & Primer & Sequence (5'-3') \\
\hline \multirow{6}{*}{$\begin{array}{l}\text { 16S rRNA gene } \\
\text { of Streptococcus } \\
\text { spp. (Primer set } \\
\text { I) }\end{array}$} & FIP & CGGCACTAAGCCCCGGAAAGTTTTGTAGTCCACGCCGTAAACG \\
\hline & $\mathrm{BIP}$ & CTGGGGAGTACGACCGCAAGTTTTCATGCTCCACCGCTTGTG \\
\hline & F3 & GTGGGGAGCAAACAGGATT \\
\hline & B3 & CCTGGTAAGGTTCTTCGCG \\
\hline & $\mathrm{LF}$ & GGCCTAACACCTAGCACTCAT \\
\hline & LB & GTTGAAACTCAAAGGAATTGACGG \\
\hline \multirow{5}{*}{$\begin{array}{l}\text { 16S-23S rRNA } \\
\text { intergenic } \\
\text { spacer of } S . \\
\text { dysgalactiae } \\
\text { (Primer set } \amalg \text { ) }\end{array}$} & FIP & TAATGGAGCCTAGCGGGATCTTTTTTAGCTCAGCTGGGAGAG \\
\hline & BIP & TGTCCATTGAAAATTGAATATCTTTTTTCTTGTTACTATTCGTACAATCA \\
\hline & F3 & GTTTTGAGAGGTCTTGTGG \\
\hline & B3 & TTCACAGCGTTTTCGGTT \\
\hline & LF & TGCGTGCAAAGCAGGCG \\
\hline \multirow{6}{*}{$\begin{array}{l}\text { 16S-23S rRNA } \\
\text { intergenic } \\
\text { spacer of } S \text {. } \\
\text { uberis (Primer } \\
\text { set III) }\end{array}$} & FIP & CTCTCCCAGCTGAGCTAAGGTTTTATTTAGTTTTGAGAGGTCTT \\
\hline & BIP & ATCCCGCTAGGCTCCATAGGTTTTCAATGGACTATACTAAGATACAATG \\
\hline & F3 & ACACGTTGGTTAAGTCTT \\
\hline & B3 & TTTCATGATCGTGGAATT \\
\hline & LF & CCCCACAGTTTGTCTCTG \\
\hline & LB & ATACAGTTCAACTGACCT \\
\hline \multirow{5}{*}{$\begin{array}{l}\text { 16S-23S rRNA } \\
\text { intergenic } \\
\text { spacer of } S . \\
\text { agalactiae } \\
\text { (Primer set IV) }\end{array}$} & FIP & CAATGGAGCCTAGCGGGATCTTTTCTTAGCTCAGCTGGGAGA \\
\hline & BIP & ATATCAAATTCCACGATCTAGAAATTTTTTTCACAGCGTTTTCGGTT \\
\hline & F3 & AGTTTTGAGAGGTCTTGTG \\
\hline & B3 & GTTTCTTTAAAACTAGAAAACTCA \\
\hline & LF & CTGACCTCCTGCGTGCAAAGC \\
\hline
\end{tabular}

\subsection{Sensitivity of the LAMP Method}

LAMP was performed in a $25 \mu \mathrm{L}$ reaction mixture containing $0.8 \mathrm{mM}$ each of FIP and BIP, $0.2 \mathrm{mM}$ each of F3 and B3, $0.4 \mathrm{mM}$ each of LF and LB, $1.0 \mathrm{mM}$ dNTPs, $20 \mathrm{mM}$ Tris- $\mathrm{HCl}$ (pH 8.8), $10 \mathrm{mM} \mathrm{KCl}, 10 \mathrm{mM}\left(\mathrm{NH}_{4}\right)_{2} \mathrm{SO}_{4}, 6 \mathrm{mM} \mathrm{MgSO}_{4}, 0.1 \%$ Triton X-100, 7.5\% DMSO [22], 1× EvaGreen, $1 \times$ Rox, serial dilutions of related DNA templates $(S$. dysgalactiae subsp. equisimilis strain ATCC 9542, S. uberis ATCC 700407 or S. agalactiae ATCC 27956) ranging from 0.01-1000 pg, and 3.2 U Bst 2.0 WarmStart DNA polymerase (New England Biolabs, Beverly, MA, USA) [23]. The reaction mixtures were heated at $57^{\circ} \mathrm{C}$ for $60 \mathrm{~min}$ in a StepOne ${ }^{\mathrm{TM}}$ System and the detection limit of conventional LAMP was determined. Negative control (no template DNA, only Tris-EDTA buffer) was included in every reaction batch. 


\subsection{Specificity of the LAMP Method}

Twenty five bacterial strains including $S$. dysgalactiae subsp. equisimilis strain ATCC 9542, S. uberis ATCC 700407 and S. agalactiae ATCC 27956 (Table 1) were used to test the specificity of the LAMP method. $100 \mathrm{pg}$ of genomic DNA were used for each reaction.

\section{Results and Discussion}

\subsection{Detection Limits of the LAMP Method}

The LAMP mixtures with the designed primers were used to detect a serial dilution of S. dysgalactiae subsp. equisimilis strain ATCC 9542, S. uberis ATCC 700407 or S. agalactiae ATCC 27956 DNA template, which were heated at $57^{\circ} \mathrm{C}$ for $60 \mathrm{~min}$. As shown in Table 3, the detection limit of all four LAMP primer sets were $0.1 \mathrm{pg}$ DNA template per reaction with no detectable false-positive response.

Table 3. Detection limits of four LAMP primer sets for identification and differentiation of Streptococcus dysgalactiae, Streptococcus uberis and Streptococcus agalactiae.

\begin{tabular}{ccccc}
\hline Bacterial strains & Primer Set I & Primer Set II & Primer Set III & Primer Set IV \\
\hline S. dysgalactiae & $0.1 \mathrm{pg}\left(4^{\mathrm{a} / 4^{\mathrm{b}}}\right)$ & $0.1 \mathrm{pg}(4 / 4)$ & - & - \\
S. uberis & $0.1 \mathrm{pg}(4 / 4)$ & - & $0.1 \mathrm{pg}(4 / 4)$ & - \\
S. agalactiae & $0.1 \mathrm{pg}(4 / 4)$ & - & - & $0.1 \mathrm{pg}(4 / 4)$ \\
\hline
\end{tabular}

Notes: Primer Set I: Method with primers targeted at 16S rRNA gene of Streptococcus spp; Primer Set II: Method with primers targeted at 16S-23S rRNA intergenic spacers of $S$. dysgalactiae; Primer Set III: Method with primers targeted at 16S-23S rRNA intergenic spacers of S. uberis; Primer Set IV: Method with primers targeted at 16S-23S rRNA intergenic spacers of $S$. agalactiae. Non-specific amplification of negative controls (false-positives) were not detected for each primer set; ${ }^{\mathbf{a}}$ Numbers of LAMP positive; ${ }^{\mathbf{b}}$ Numbers of total experiments carried out.

\subsection{Specificity of the LAMP Method}

Primers targeting the 16S rRNA gene of Streptococcus spp. were used to test the specificity of the LAMP method. In addition, S. dysgalactiae subsp. equisimilis strain ATCC 9542, S. uberis ATCC 700407 and S. agalactiae ATCC 27956 were also included in the LAMP assay. As shown in Table 1, these three strains were successfully detected. 22 non-Streptococcus strains were also included in the LAMP assays, all four repeated reactions of any non-Streptococcus strain were negative.

The LAMP method with primer sets targeting the 16S-23S rRNA intergenic spacers of S. dysgalactiae, S. uberis and S. agalactiae were also tested with25 strains (Table 1). S. dysgalactiae subsp. equisimilis strain ATCC 9542, S. uberis ATCC 700407 and S. agalactiae ATCC 27956 were successfully detected, respectively, while all other reactions were negative (Table 1).

Therefore, the four LAMP primer sets presented here can identify and differentiate S. dysgalactiae, S. uberis and $S$. agalactiae with high specificity. 


\section{Conclusions}

Phenotypic characteristics cannot be used to identify sub-clinical mastitis, and bacterial culturing methods are complex and labor intensive, therefore, genotypic methods are generally used for bacterial identification for sub-clinical mastitis. Molecular methods based on the 16S rRNA gene sequences are robust, reproducible, and accurate [24]. In this study, a set of LAMP primers (primer set I) targeting the 16S rRNA gene of Streptococcus spp. was designed for loop-mediated isothermal amplification (LAMP), the LAMP method can be successfully used to identify of Streptococcus spp. at the genus level.

16S-23S rRNA intergenic spacers have been used to differentiate probiotic lactic acid bacteria [25], acetic acid bacteria [26], and Vibrio species [27]. A previous study showed that staphylococci and streptococci that cause bovine mastitis can be identified via 16S-23S rRNA intergenic spacers [28]. Therefore, three sets of LAMP primers targeting the 16S-23S rRNA intergenic spacers of $S$. dysgalactiae, S. uberis and $S$. agalactiae were designed, respectively. The corresponding three LAMP primer sets can favorably differentiate $S$. dysgalactiae, $S$. uberis and $S$. agalactiae at species levels.

The LAMP method with four sets of primers developed in this study are rapid, sensitive and specific, which may be helpful in field studies of diagnosis and effective treatment, antibiotic selection, and control of mastitis.

\section{Acknowledgments}

The authors would like to acknowledge the China Scholarship Council. This work was supported by Natural Science Foundation of China (31172331), NSFC-Henan Talent Training Joint Foundation (U1204330), Project for Scientific Research \& Innovation Team of Henan Universities (15IRTSTHN016), Foundation of Henan Province for Excellent Young Teachers of Colleges and Universities (2012GGJS-172), Project of Xuchang University for Outstanding Young Backbone Teachers, and Training Project for Outstanding Youth Backbone Personnel of Xuchang University.

\section{Author Contributions}

Deguo Wang performed the experiments; Yanhong Liu wrote the paper and designed the experiments.

\section{Conflicts of Interest}

The authors declare no competing interest.

\section{References}

1. Watts, J.L. Etiological agents of bovine mastitis. Vet. Microbiol. 1988, 16, 41-66.

2. Riffon, R.; Sayasith, K.; Khalil, H.; Dubreuil, P.; Drolet, M.; Lagacé, J. Development of a rapid and sensitive test for identification of major pathogens in bovine mastitis by PCR. J. Clin. Microbiol. 2001, 39, 2584-2589.

3. Smith, K.L.; Todhunter, D.A.; Schoenberger, P.S. Environmental mastitis: Cause, prevalence, prevention. J. Dairy Sci. 1985, 68, 1531-1553. 
4. Prabhu, K.N.; Isloor, S.; Hegde, R.; Rathnamma, D.; Beeregowda, B.M.; Murthy, H.N.N.; Shome, R.; Suryanarayana, V.V.S. Development of polymerase chain reaction for detection of predominant streptococcal isolates causing subclinical bovine mastitis. Indian J. Biochem. Biophys. 2013, 12, 208-212.

5. Phuektes, P.; Browning, G.F.; Anderson, G.; Mansell, P.D. Multiplex polymerase chain reaction as a mastitis screening test for Staphylococcus aureus, Streptococcus agalactiae, Streptococcus dysgalactiae and Streptococcus uberis in bulk milk samples. J. Dairy Res. 2003, 70,149-155.

6. Koskinen, M.T.; Holopainen, J.; Pyörälä, S.; Bredbacka, P.; Pitkälä, A.; Barkema, H.W.; Bexiga, R.; Roberson, J.; Sølverød, L.; Piccinini, R.; Kelton, D.; Lehmusto, H.; Niskala, S.; Salmikivi, L. Analytical specificity and sensitivity of a real-time polymerase chain reaction assay for identification of bovine mastitis pathogens. J. Dairy Sci. 2009, 92, 952-959.

7. Španová, A.; Rittich, B.; Karpíšková, R.; Čechová, L.; Škapová, D. PCR identification of Salmonella cells in food and stool samples after immunomagnetic separation. Bioseparation 2000, 9, 379-384.

8. Al-Soud, W.A.; Rådström, P. Purification and characterization of PCR-inhibitory components in blood cells. J. Clin. Microbiol. 2001, 39, 485-493.

9. Wilson, I.G. Inhibition and facilitation of nucleic acid amplification. Appl. Environ. Microbiol. 1997, 63, 3741-3751.

10. Notomi, T.; Okayama, H.; Masubuchi, H.; Yonekawa, T.; Watanabe, K.; Amino, N.; Hase, T. Loop-mediated isothermal amplification of DNA. Nucleic Acid Res. 2000, doi:10.1093/nar/ 28.12.e63.

11. Nagamine, K.; Hase, T.; Notomi, T. Accelerated reaction by loop-mediated isothermal amplification using loop primers. Mol. Cell. Probes 2002, 16, 223-229.

12. Fakruddin, M. Loop mediated isothermal amplification (LAMP) - An alternative to polymerase chain reaction (PCR). Bangladesh Res. Publ. J. 2011, 5, 425-439.

13. Maruyama, F.; Kenzaka, T.; Yamaguchi, N.; Tani, K.; Nasu, M. Detection of bacteria carrying the stx2 gene by in situ loop-mediated isothermal amplification. Appl. Environ. Microbiol. 2003, 69, 5023-5028.

14. Osawa, R.; Yoshida, A.; Masakiyo, Y.; Nagashima, S.; Ansai, T.; Watari, H.; Notomi, T.; Takehara, T. Rapid detection of Actinobacillus actinomycetemcomitans using a loop-mediated isothermal amplification method. Oral Microbiol. Immunol. 2007, 22, 252-259.

15. Iwamoto, T.; Sonobe, T.; Hayashi, K. Loop-mediated isothermal amplification for direct detection of Mycobacterium tuberculosis complex, M. avium, and M. intracellulare in sputum samples. J. Clin. Microbiol. 2003, 41, 2616-2622.

16. Seki, M.; Yamashita, Y.; Torigoe, H.; Tsuda, H.; Sato, S.; Maeno, M. Loop-mediated isothermal amplification method targeting the lytA gene for detection of Streptococcus pneumoniae. J. Clin. Microbiol. 2005, 43, 1581-1586.

17. Tang, M.J.; Zhou, S.; Zhang, X.Y.; Pu, J.H.; Ge, Q.L.; Tang, X.J.; Gao, Y.S. Rapid and sensitive detection of Listeria monocytogenes by loop-mediated isothermal amplification. Curr. Microbiol. 2011, 63, 511-516. 
18. Hwang, S.Y.; Kim, S.H.; Jang, E.J.; Kwon, N.H.; Park, Y.K.; Koo, H.C.; Jung, W.K.; Kim, J.M.; Park, Y.H. Novel multiplex PCR for the detection of the Staphylococcus aureus superantigen and its application to raw meat isolates in Korea. Int. J. Food Microbiol. 2007, 117, 99-105.

19. Lim, K.T.; Ju, C.S.; Thong, K.L. Loop-mediated isothermal amplification assay for the rapid detection of staphylococcus aureus. Biomed. Res. Int. 2013, doi:10.1155/2013/895816.

20. Kimura, K.; Yanagisawa, H.; Wachino, J.; Shibayama, K.; Arakawa, Y. Rapid and reliable loop-mediated isothermal amplification method for detecting streptococcus agalactiae. Jpn. J. Infect. Dis. 2013, 66, 546-548.

21. Li, S.L.; Zhang, X.B.; Wang, D.G.; Kuang, Y.Y.; Xu, Y.G. Simple and rapid method for detecting foodborne shigella by a loop-mediated isothermal amplification. J. Rapid Meth. Aut. Mic. 2009, $17,465-475$.

22. Frackman, S.; Kobs, G.; Simpson, D.; Storts, D. Betaine and DMSO: Enhancing agents for PCR. Promega Notes 1998, 65, 27-29.

23. Misawa, Y.; Yoshida, A.; Saito, R.; Yoshida, H.; Okuzumi, K.; Ito, N.; Okada, M.; Moriya, K.; Koike, K. Application of loop-mediated isothermal amplification technique to rapid and direct detection of methicillin-resistant Staphylococcus aureus (MRSA) in blood cultures. J. Infect. Chemother. 2007, 13, 134-140.

24. Clarridge, J.E. Impact of $16 \mathrm{~S}$ rRNA gene sequence analysis for identification of bacteria on clinical microbiology and infectious diseases. Clin. Microbiol. Rev. 2004, 17, 840-862.

25. Tilsala-Timisjärvi, A.; Alatossava, T. Development of oligonucleotide primers from the $16 \mathrm{~S}-23 \mathrm{~S}$ rRNA intergenic sequences for identifying different dairy and probiotic lactic acid bacteria by PCR. Int. J. Food Microbiol. 1997, 35, 49-56.

26. González, A.; Mas, A. Differentiation of acetic acid bacteria based on sequence analysis of $16 \mathrm{~S}-23 \mathrm{~S}$ rRNA gene internal transcribed spacer sequences. Int. J. Food Microbiol. 2011, 147, 217-222.

27. Hoffmann, M.; Brown, E.W.; Feng, P.C.H.; Keys, C.E.; Fischer, M.; Monday, S.R. PCR-based method for targeting 16S-23S rRNA intergenic spacer regions among Vibrio species. BMC Microbiology 2010, doi:10.1186/1471-2180-10-90.

28. Forsman, P.; Tilsaia-Timisjärvi, A.; Alatossava, T. Identification of staphylococcal and streptococcal causes of bovine mastitis using 16S-23S rRNA spacer regions. Microbiology 1997, $143,3491-3500$.

(C) 2015 by the authors; licensee MDPI, Basel, Switzerland. This article is an open access article distributed under the terms and conditions of the Creative Commons Attribution license (http://creativecommons.org/licenses/by/4.0/). 